\title{
Analisa kinerja simpang BCP (Bekasi Cyber Park) saat pembangunan tol Becakayu section 2A menggunakan PTV Vissim
}

\author{
Utamy S Saputri a,1, ${ }^{*}$, Adi Iranda Ayusdira b,2, Ardin Rozandi b,3 Tsulis lqbal b,4 \\ a IPB University, Bogor, Indonesia

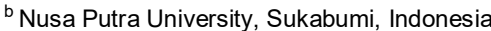 \\ 1 utamy.sukmayu@nusaputra.ac.id*; ${ }^{2}$ adi.iranda_ts17@nusaputra.ac.id; ${ }^{3}$ ardin.rozandi@nusaputra.ac.id ${ }^{4}$ tsulis.iqbal@nusaputra.ac.id \\ * Corresponding Author
}

\section{ABSTRAK}

ingginya tingkat pertumbuhan masyarakat menimbulkan adanya peningkatan kebutuhan untuk menjalani aktivitas sehari-hari, khususnya di bidang transportasi, sarana dan prasarana. Seiring dengan meningkatnya penggunaan moda transportasi menyebabkan bertambahnya mobilitas masyarakat dan mengakibatkan peningkatan kapasitas lalu lintas yang menyebabkan kemacetan. Sebagaimana kasus kemacetan pada simpang BCP (Bekasi Cyber Park) yang terkena dampak dari pembangunan Tol Becakayu Section 2A. Sistem pelayanan sinyal pada simpang tersebut masih menggunakan cara manual searah jarum jam. Penelitian ini bertujuan untuk menganalisa, mengevaluasi, dan memodelkan sebagaimana kinerja pada simpang tersebut. Metode yang digunakan dalam mengkaji permasalahan ini dengan pedoman Manual Kapasitas Jalan Indonesia 1997 dan pemodelan software PTV VISSIM Student Version, data yang digunakan yaitu volume jam puncak. Hasil analisis kinerja Simpang BCP 2 fase dengan metode Manual Kapasitas Jalan Indonesia (MKJI) 1997 dan melalui pemodelan PTV VISSIM pada kondisi eksisting atau saat pembangunan tol Becakayu, menunjukan tingkat rata-rata pelayanan (LOS_E), Panjang antrian rata-rata (Qlen) sebesar $115 \mathrm{~m}$, dan tundaan simpang (VehDelay) sebesar $52.69 \mathrm{det} / \mathrm{skr}$. Dengan hasil kondisi eksisting tersebut maka sangatlah penting adanya evaluasi dalam meningkatkan kinerja lalu lintas, terkait kondisi simpang BCP dikarenakan kondisi existing saat pembangunan JI. KH Noer Ali \& JI. Mayor Madmuin Hasibuan masih beroperasi

\section{Analysis of the Performance Bcp Intersection (Bekasi Cyber Park) During the Construction of Becakayu Section $2 A$ Toll Using Ptv Vissim}

\section{ABSTRACT}

The high rate of community growth has led to an increase in the need to carry out daily activities, especially in the field of transportation, facilities and infrastructure. Along with the increasing use of transportation modes, it causes increased community mobility and results in an increase in traffic capacity which causes congestion. As in the case of congestion at the BCP (Bekasi Cyber Park) intersection which was affected by the construction of the Becakayu Section $2 A$ Toll Road. The signal service system at the intersection still uses a clockwise manual method. This study aims to analyze, evaluate, and model the performance at the intersection. The method used in assessing this problem is the 1997 Indonesian Road Capacity Manual and PTV VISSIM Student Version software modeling, the data used is the peak hour volume. The results of the analysis of the performance of the 2-phase BCP Intersection using the 1997 Indonesian Road Capacity Manual (MKJI) method and through PTV VISSIM modeling in the existing conditions or during the construction of the Becakayu toll road, show the average level of service (LOS_E), the average queue length (Qlen) of $115 \mathrm{~m}$, and the intersection delay (VehDelay) is $52.69 \mathrm{sec} / \mathrm{cur}$. With the results of the existing conditions, it is very important to evaluate in improving traffic performance, related to the condition of the $B C P$ intersection due to the existing conditions during the construction of Jl. KH Noer Ali \& Jl. Major Madmuin Hasibuan is still operating

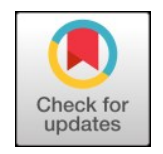

\section{KATA KUNCI}

Kinerja Simpang

MKJI 1997

PTV VISSIM

Simpang BCP

Tol Becakayu Section 2A

\section{KEYWORDS}

Intersection Performance

MKJI 1997

PTV VISSIM

BCP Intersection

Becakayu Toll Road Section $2 A$ 


\section{Pendahuluan}

Indonesia merupakan negara dengan jumlah penduduk terpadat ke empat di dunia [1], [2]. Pertumbuhan total populasinya sekitar 267 juta jiwa. Semakin tinggi tingkat pertumbuhan maka tingkat kebutuhan masyarakat untuk menjalani aktivitas sehari-hari akan semakin bertambah, khususnya di bidang transportasi, sarana dan prasarana [3]. Seiring dengan meningkatnya penggunaan moda transportasi menyebabkan bertambahnya mobilitas masyarakat dan mengakibatkan peningkatan kapasitas lalu lintas yang menyebabkan kemacetan [4]-[6]. Jakarta sebagai ibu kota negara yang terletak di pesisir bagian barat laut Pulau Jawa, merupakan pusat bisnis dan pusat pemerintahan dengan jumlah penduduk yang cukup padat. Kota Jakarta tidak hanya diisi oleh masyarakat yang bertempat tinggal di Jakarta saja, melainkan banyak masyarakat dari luar wilayah Jakarta pun melakukan kegiatan sehari-harinya di sana. Salah satu penguhubung jalan Jakarta dan Bekasi adalah Jalan Raya Kalimalang. Dimana Jalan Raya Kalimalang belum bisa mencukupi untuk menampung volume kendaraan yang mengalami kenaikan sangat pesat dan tidak seimbang dengan pertumbuhan jalan [7]-[9]. Untuk mengatasi ketidakseimbangan tersebut salah satu cara yang dilakukan oleh pemerintah adalah dengan membangun jalan termasuk diantaranya yakni jalan Tol. Jalan Tol yang dibangun berada di atas sungai Kalimalang, yang bertujuan untuk mengatasi kemacetan di koridor tersebut. Jalan Tol yang dibangun, akan menghubungkan Kampung Melayu yang berada di Jakarta Timur sampai dengan Tambun, Bekasi. Selain membangun tol, pemerintah juga akan membebaskan lahan untuk melebarkan Jalan Raya Kalimalang mulai dari ruas Jalan KH Noer Ali hingga Jalan Inspeksi Saluran Kalimalang di Cawang yang lokasinya berada di sepanjang Jalan Raya Kalimalang [10]-[13].

Jalan A Yani dan Jalan KH Noer Ali merupakan kawasan bisnis, sehingga apa yang terjadi di kota Jakarta akan mempengaruhi secara langsung dan berdampak cepat terhadap kawasan bisnis ini. Koridor Jalan A Yani dan Jalan KH Noer Ali, memiliki arti penting bagi pertumbuhan kota Bekasi secara keseluruhan. Adanya pembangunan Jalan Tol Becakayu yang sudah memasuki seksi ke-2A, dimana seksi ini berada di Jalan KH Noer Ali sampai Jalan Veteran, tentunya sangat berdampak untuk Jalan KH Noer Ali sampai Jalan Veteran. Hal ini dikarenakan pada saat proses pembangunan, sebagian jalan masih digunakan oleh pengguna jalan, sehingga menyebabkan lajur pada Jalan $\mathrm{KH}$ Noer Ali mengalami pengurangan dan kemacetan. Tentunya kondisi seperti ini perlu diperhitungkan kinerja pada ruas jalan dan simpang yang terkena dampak dari pembangunan Tol Becakayu ini [14], [15].

\section{Metode}

\subsection{Lokasi Penelitian}

Lokasi penelitian dilakukan pada jalan eksisting yang terkena dampak dari Alignment Tol Becakayu, Jl.KH Noer Ali, Jl Ahmad Yani Utara dan Jl. Mayor Madmuin Hasibuan, terilaht pada Gambar 1. Penelitian dilakukan dengan survey langsung ke lokasi Simpang BCP. Pengambilan data diambil selama satu hari, yaitu pada satu hari kerja, selama 2 jam pada waktu pagi dan sore. Dengan pembagian waktu sebagai berikut; (1) Pagi hari, Pukul 06:00 - 08:00 WIB; (2) Sore hari, Pukul 16:00 - 18:00 WIB

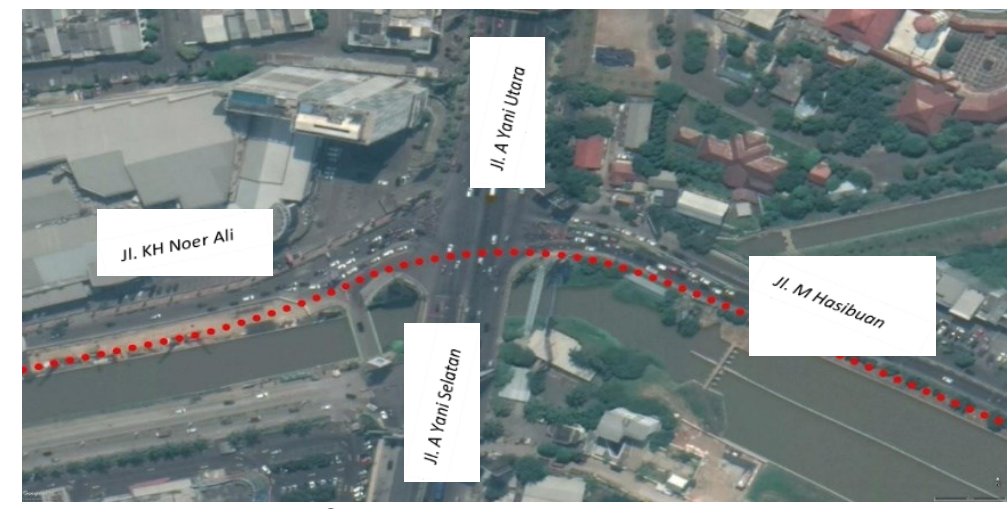

Gambar 1. Peta Lokasi Penelitian 


\subsection{Alat dan Bahan}

Alat dan bahan yang digunakan untuk penelitian adalah sebagai berikut; Formulir penelitian; alat ukur (Roll Meter); hand counter; Speed gun; alat tulis; kendaraan survey; kamera; laptop.

\subsection{Tahapan Penelitian}

Tahapan penelitian ini dimulai dari studi literature, menentukan lokasi penelitian, menyediakan alatalat penelitian, mengumpulkan data yang terdiri dari data primer, dan data sekunder, selanjutnya dilakukan analisis dan pembahasan, dan terakhir ditarik kesimuplan, paparan tersebut dapat terlihat pada Gambar 2.

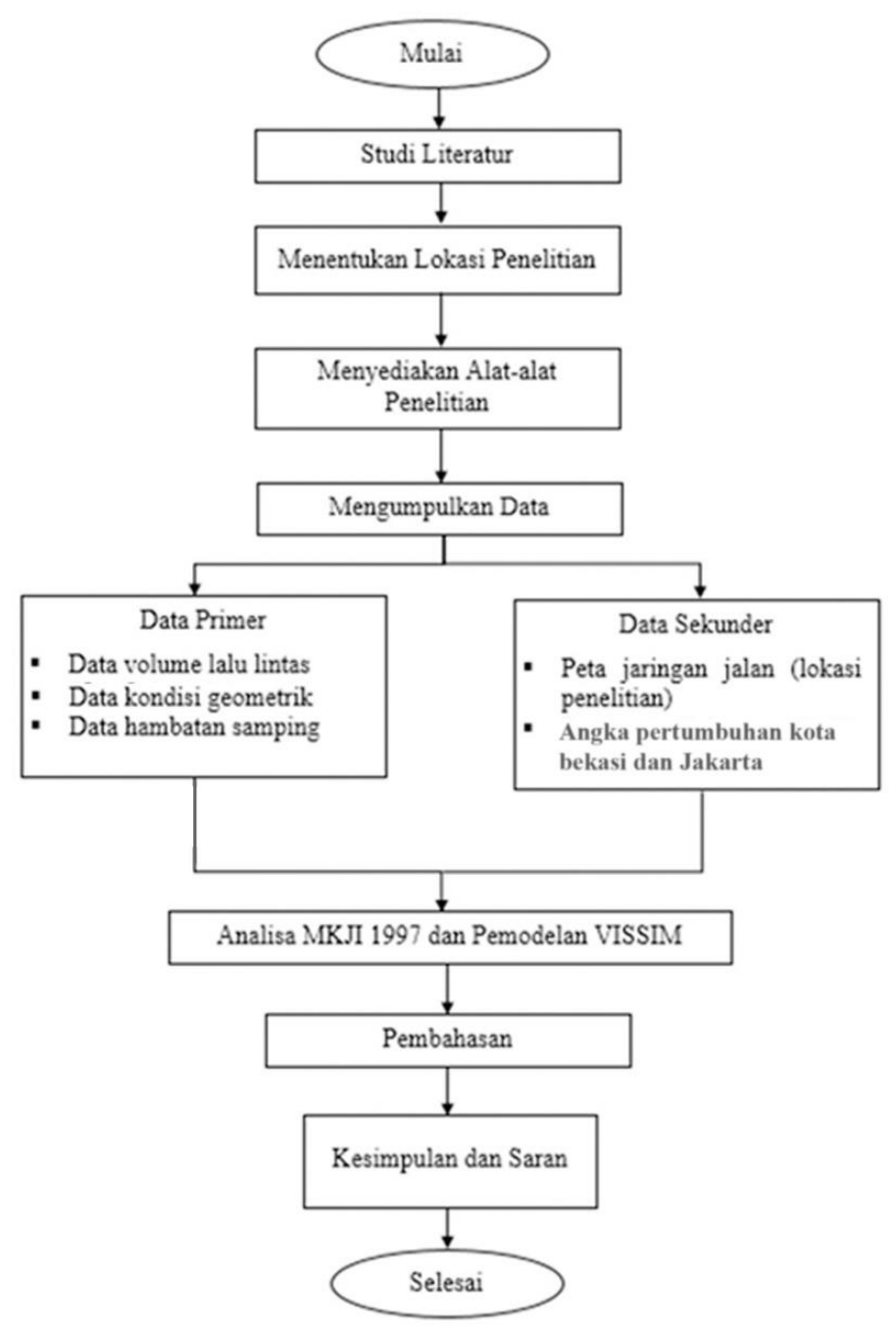

Gambar 2. Diagram Alir

\subsection{Analisis Data}

Analisis data pada penelitian ini menggunakan dua acuan pembeda yaitu Manual Kapasitas Jalan Indonesia (MKJI) 1997 sebagai hasil rekapitulasi survei lalu lintas dan software PTV VISSIM sebagai hasil pemodelan simulasi lalu lintas. Dari kedua analisis tersebut akan menghasilkan nilai analisis kinerja simpang.

\subsubsection{Analisis Metode MKJI 1997}

Manual Kapasitas Jalan Indonesia (MKJI) 1997 merupakan paduan untuk menghitung kapasitas dan perilaku lalu lintas pada segmen-segmen jalan di Indonesia. perhitungan MKJI 1997 digunakan sebagai acuan untuk melihat suatu kinerja simpang. Hasil yang diperoleh dari analisis ini berupa derajat kejenuhan (DS), panjang antrian (QL), dan tundaan (T). 
- Derajat Kejenuhan (DS); Derajat kejenuhan adalah rasio arus lalu lintas terhadap kapasitas, yang digunakan sebagai faktor utama dalam melihat kinerja simpang.

$\mathrm{DS}=\mathrm{Q} / \mathrm{C}$

- Panjang Antrian (QL); Data hasil perhitungan derajat kejenuhan (DS), kemudian digunakan sebagai perhitungan jumlah antrian (NQ1) yaitu kendaraan yang tersisa dari fase hijau sebelumnya. Untuk DS > 0,5: Data hasil perhitungan derajat kejenuhan (DS), kemudian digunakan sebagai perhitungan jumlah antrian (NQ2) yaitu jumlah antrian kendaraan yang datang selama fase merah. Untuk nilai (NQmax) diperoleh menggunakan grafik dari MKJI 1997. Dengan menghubungkan nilai NQ dan probabilitas overloading POL (\%). Untuk perencanaan dan desain digunakan POL $<5 \%$ sedangkan untuk operasional atau kinerja POL $5-10 \%$.

$\mathrm{QL}=\mathrm{NQmax} \times(20 / \mathrm{Wmasuk}$

- Tundaan; Perhitungan tundaan terbagi menjadi dua yaitu tundaan lalu lintas rata-rata (DT) dan tundaan geometri (DG); (1) Tundaan Lalu Lintas (DT); (2) Tundaan Geometri (DG).

$\mathrm{DG}=(1-\mathrm{Psv}) \times \mathrm{PT}$

Menghitung analisis tundaan rata-rata (D) dan tundaan total kondisi eksisting: Tundaan rata-rata (D):

Tundaan total:

$\mathrm{D}=\mathrm{DT}+\mathrm{DG}$

Dtot $=\mathrm{D} \times \mathrm{QD}$ to

\subsubsection{Pemodelan PTV VISSIM}

Memodelkan simpang bersinyal berdasarkan data-data yang sudah diperoleh dari hasil survei dan perhitungan seperti geometrik, arus lalu lintas, dan kecepatan kendaraan, kemudian memasukanya ke program software PTV VISSIM (student version). Hasil yang diperoleh dari pemodelan ini berupa nilai panjang antrian (Qlen), tingkat pelayanan (LOS) dan tundaan (VehDelay).

\section{Hasil dan Pembahasan}

Pengumpulan data dilakukan sesuai dengan acuan yang tertulis pada bab sebelumnya, jenis data yang digunakan dalam penelitian ini adalah data primer dan sekunder yang yang diperoleh dari hasil survey volume kendaraan, kecepatan, dan geometrik untuk ruas jalan dan simpang.

\subsection{Analisis Kondisi Geometrik}

Pada Tabel 1 menunjukkan kondisi geometrik ruas jalan sebelum proyek yang menggabarkan tipe lebar jalan dan kelas hambatan samping. Badan jalan terlebar ditunjukkan pada ruas jalan Jl. Jend Ahmad Yani Utara, diikuti Jl. Jend Ahmad Yani Selatan, Jl. Mayor Madmuin Hasibuan, Jl. KH Noer Ali.

Tabel 1. Kondisi geometrik ruas jalan sebelum proyek

\begin{tabular}{|c|c|c|c|c|c|}
\hline \multicolumn{6}{|c|}{ Lebar } \\
\hline Ruas Jalan & \multicolumn{4}{|c|}{$\underset{\text { (m) }}{\text { Tipe JalanBadan Jalan }}$ Lajur (m)Median (m) } & Kelas HambatanSamping \\
\hline J1. KH Noer Ali & $4 / 2 \mathrm{D}$ & 15.7 & 3.925 & 1 & Tinggi \\
\hline Jl. Jend Ahmad Yani Selatan & $8 / 2 \mathrm{D}$ & 25 & 3.125 & 1.3 & Tinggi \\
\hline Jl. Jend Ahmad Yani Utara & $8 / 2 \mathrm{D}$ & 27 & 3.375 & 0.5 & Tinggi \\
\hline J1. Mayor Madmuin Hasibuan & $4 / 2 \mathrm{D}$ & 18.2 & 4.55 & 0.9 & Tinggi \\
\hline
\end{tabular}

Sumber : Bina Infrastruktur Antarnusa, 2019

Pada Tabel 2 dijelaskan mengenai kondisi geometrik ruas jalan saat proyek pembangunan. Badan jalan terlebar ditunjukkan pada jalan Jend Ahmad Yani Utara, diikuti oleh jalan Jend Ahmad Yani Selatan, disusul jalan Mayor Madmuin Hasibuan, dan terakhir jalan KH Noer Ali. 
Tabel 2. Kondisi geometrik ruas jalan saat proyek pembangunan

\begin{tabular}{|c|c|c|c|c|c|}
\hline \multirow[b]{2}{*}{ Ruas Jalan } & \multirow[b]{2}{*}{ Tipe Jalan } & \multicolumn{3}{|c|}{ Lebar } & \multirow[b]{2}{*}{ Kelas HambatanSamping } \\
\hline & & $\begin{array}{c}\text { Badan } \\
\text { Jalan(m) }\end{array}$ & Lajur (m) & Median(m) & \\
\hline Jl. KH Noer Ali & $2 / 1$ & 7.9 & 3.925 & - & Tinggi \\
\hline Jl. Jend Ahmad Yani Selatan & $8 / 2 \mathrm{D}$ & 25 & 3.125 & - & Tinggi \\
\hline Jl. Jend Ahmad Yani Utara & $8 / 2 \mathrm{D}$ & 27 & 3.375 & - & Tinggi \\
\hline Jl. Mayor Madmuin Hasibuan & $2 / 1$ & 9.1 & 4.55 & - & Tinggi \\
\hline
\end{tabular}

\subsection{Volume Arus Lalu Lintas}

Data hasil survei volume lalu lintas di lapangan pada satu hari yang sama yaitu pagi pukul 06:00 08:00 WIB, dan sore pukul 16:00 - 18:00 WIB. Didapatkan perbandingan volume jam puncak dalam satuan kend/jam dapat terlihat pada Tabel 3.

Tabel 3. Volume kendaraan pada ruas jalan eksisting pada pagi hari.

\begin{tabular}{|c|c|c|c|c|}
\hline Waktu & \multicolumn{2}{|c|}{ Arah } & Arus Total & Jumlah \\
\hline & & & & \multirow{3}{*}{4,755} \\
\hline $06.00-07.00$ & \multirow{2}{*}{ Jl.Jend. Ahmad Yani Utr } & \multirow{2}{*}{ Jl.Jend. Ahmad Yani Sel } & 2,386 & \\
\hline $07.00-08.00$ & & & 2,369 & \\
\hline $06.00-07.00$ & \multirow{2}{*}{$\begin{array}{l}\text { Jl. Mayor Madmuin Hasibuan } \\
\text { Tmr }\end{array}$} & \multirow[t]{2}{*}{ Jl.Jend. Ahmad Yani Sel } & 398 & \multirow[t]{2}{*}{810} \\
\hline $07.00-08.00$ & & & 412.3 & \\
\hline $06.00-07.00$ & \multirow{2}{*}{ Jl. KH. Noer Ali Brt } & \multirow{2}{*}{ Jl.Jend. Ahmad Yani Sel } & 751 & \multirow{2}{*}{1,475} \\
\hline $07.00-08.00$ & & & 724.3 & \\
\hline $06.00-07.00$ & \multirow{2}{*}{$\begin{array}{l}\text { Jl. Mayor Madmuin Hasibuan } \\
\text { Tmr }\end{array}$} & \multirow[t]{2}{*}{ Jl.Jend. Ahmad Yani Utr } & 802 & \multirow[t]{2}{*}{802} \\
\hline $07.00-08.00$ & & & 803,35 & \\
\hline $06.00-07.00$ & \multirow{2}{*}{ Jl.Jend. Ahmad Yani Sel } & \multirow{2}{*}{ Jl.Jend. Ahmad Yani Utr } & 2,450 & \multirow{2}{*}{4,861} \\
\hline $07.00-08.00$ & & & $2,411.20$ & \\
\hline $06.00-07.00$ & \multirow{2}{*}{ Jl. KH. Noer Ali Brt } & \multirow{2}{*}{ Jl.Jend. Ahmad Yani Utr } & 751 & \multirow{2}{*}{1,475} \\
\hline $07.00-08.00$ & & & 724.3 & \\
\hline
\end{tabular}

Volume Kendaraan Pagi hari. Volume kendaraan pada ruas jalan eksisting pada sore hari terlihat pada Tabel 4.

Tabel 4. Volume Kendaraan Sore hari

\begin{tabular}{|c|c|c|c|c|}
\hline Waktu & \multicolumn{2}{|c|}{ Arah } & Arus Total & Jumlah \\
\hline & \multirow{3}{*}{ Jl.Jend. Ahmad Yani Utr } & \multirow{3}{*}{ Jl.Jend. Ahmad Yani Sel } & & \multirow{3}{*}{$3,302.75$} \\
\hline $16.00-17.00$ & & & $2,197.55$ & \\
\hline $17.00-18.00$ & & & $1,105.20$ & \\
\hline $16.00-17.00$ & \multirow{2}{*}{$\begin{array}{l}\text { Л. Mayor Madmuin Hasibuan } \\
\text { Tmr }\end{array}$} & \multirow[t]{2}{*}{ Jl.Jend. Ahmad Yani Sel } & 532.6 & \multirow[t]{2}{*}{$1,036.20$} \\
\hline $17,00-18,00$ & & & 503.6 & \\
\hline $16.00-17.00$ & \multirow{2}{*}{ Jl. KH. Noer Ali Brt } & \multirow{2}{*}{ Jl.Jend. Ahmad Yani Sel } & 598.6 & \multirow{2}{*}{$1,205.80$} \\
\hline $17.00-18.00$ & & & 607.2 & \\
\hline $16.00-17.00$ & \multirow[t]{2}{*}{$\begin{array}{l}\text { Л. Mayor Madmuin Hasibuan } \\
\text { Tmr }\end{array}$} & \multirow[t]{2}{*}{ Jl.Jend. Ahmad Yani Utr } & $1,407.50$ & \multirow[t]{2}{*}{$2,025.80$} \\
\hline $17.00-18.00$ & & & 618.30 & \\
\hline $16.00-17.00$ & \multirow{2}{*}{ Jl.Jend. Ahmad Yani Sel } & \multirow{2}{*}{ Jl.Jend. Ahmad Yani Utr } & $2,541,45$ & \multirow{2}{*}{$3,109.15$} \\
\hline $17.00-18.00$ & & & 567.70 & \\
\hline $16.00-17.00$ & \multirow[t]{2}{*}{ Jl. KH. Noer Ali Brt } & \multirow[t]{2}{*}{ JI.Jend. Ahmad Yani Utr } & 245,1 & \multirow[t]{2}{*}{486} \\
\hline $17.00-18.00$ & & & 240.9 & \\
\hline
\end{tabular}


Volume jam puncak (VJP) diketahui pada pagi hari dengan total volume kendaraan mencapai 4.418 $\mathrm{kend} / \mathrm{jam}$, dan ini terlihat pada Tabel 5.

\begin{tabular}{|c|c|c|c|c|c|}
\hline \multirow{2}{*}{ KODE PENDEKAT } & \multirow{2}{*}{ ARAH } & \multicolumn{3}{|c|}{$\begin{array}{l}\text { ARUS LALU LINTAS KENDARAAN } \\
\text { BERMOTOR }\end{array}$} & \multirow{2}{*}{ 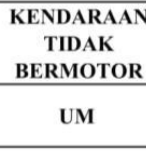 } \\
\hline & & $\begin{array}{c}\text { LV } \\
\text { (Kend/jam) }\end{array}$ & $\begin{array}{c}\text { HV } \\
\text { (Kend/jam) }\end{array}$ & $\begin{array}{c}\text { MC } \\
\text { (Kend/jam) } \\
\end{array}$ & \\
\hline \multirow[t]{2}{*}{$\mathbf{U}$} & $\begin{array}{c}\text { Jl. Ahmad Yani Utara - Jl. Ahmad } \\
\text { Yani Selatan }\end{array}$ & 1.987 & 510 & 2.258 & 31 \\
\hline & Total & \multicolumn{3}{|c|}{4.755} & 31 \\
\hline \multirow[t]{2}{*}{ S } & $\begin{array}{c}\text { Jl. Ahmad Yani Selatan- Jl. Ahmad } \\
\text { Yani Utara }\end{array}$ & 1.433 & 453 & 2.975 & 17 \\
\hline & Total & \multicolumn{3}{|c|}{4.861} & 17 \\
\hline \multirow{3}{*}{ B } & $\begin{array}{c}\text { Jl. KH Noer Ali - Jl. Ahmad Yani } \\
\text { Utara }\end{array}$ & 551 & 242 & 682 & 25 \\
\hline & $\begin{array}{l}\text { Jl. KH Noer Ali - Jl. Ahmad Yani } \\
\text { Selatan }\end{array}$ & 643 & 264 & 568 & 33 \\
\hline & Total & \multicolumn{3}{|c|}{2.950} & 58 \\
\hline \multirow{3}{*}{$\mathbf{T}$} & $\begin{array}{l}\text { Jl. Mayor Madmuin Hasibuan - Jl. } \\
\text { Ahmad Yani Utara }\end{array}$ & 292 & 84 & 426 & 19 \\
\hline & $\begin{array}{l}\text { Jl. Mayor Madmuin Hasibuan - Jl. } \\
\text { Ahmad Yani Selatan }\end{array}$ & 186 & 90 & 534 & 23 \\
\hline & Total & \multicolumn{3}{|c|}{1.612} & 42 \\
\hline
\end{tabular}

Tabel 5. Arus Kendaraan Bermotor

Penjelasan Tabel 5 adalah sebagai berikut; LV adalah Kendaraan Ringan (Mobil penumpang), HV merupakan Kendaraan Berat (Truk Besar, Truk kecil, bus besar, bus kecil ), dan MC merupakan Sepeda Motor, serta UM adalah Kendaraan Tidak bermotor. Analisa Perhitungan Simpang BCP menggunakan 2 Fase antara lain: Menghitung Waktu Siklus (Co), Waktu Hijau (G), Kapasitas C \& Derajat kejenuhan. Dapat dilihat pada Gambar 3.

\begin{tabular}{|c|c|c|c|c|}
\hline $\begin{array}{c}\text { Kode } \\
\text { Pendekat }\end{array}$ & $\mathbf{U}$ & S & $\mathbf{T}$ & B \\
\hline Fase & \multicolumn{2}{|c|}{1} & \multicolumn{2}{|c|}{2} \\
\hline $\begin{array}{c}\text { Arus (q) } \\
(\text { kend/jam) }\end{array}$ & 3102 & 2617 & 896 & 2102 \\
\hline $\begin{array}{l}\text { Arus Jenuh (s) } \\
\text { (kend/jam) }\end{array}$ & 8100 & 7500 & 5460 & 4740 \\
\hline $\mathrm{y}$ & 0.38 & 0.35 & 0.16 & 0.44 \\
\hline $\mathrm{y}$ kritis & \multicolumn{2}{|c|}{0.38} & \multicolumn{2}{|c|}{0.44} \\
\hline $\mathrm{Y}$ & \multicolumn{4}{|c|}{0.83} \\
\hline L (detik) & \multicolumn{4}{|c|}{12} \\
\hline Co (detik) & \multicolumn{4}{|c|}{107} \\
\hline $\begin{array}{c}\text { Waktu hijau } \\
\text { total persiklus ( } \\
\text { detik ) }\end{array}$ & \multicolumn{4}{|c|}{95} \\
\hline $\mathrm{g}$ (detik) & \multicolumn{2}{|c|}{43.80} & \multicolumn{2}{|c|}{50.72} \\
\hline G (detik) & \multicolumn{2}{|c|}{46.80} & \multicolumn{2}{|c|}{53.72} \\
\hline $\begin{array}{c}\text { Kapsasitas C } \\
\text { (kend/jam) }\end{array}$ & 3330.63 & 3083.92 & 2599.84 & 2570 \\
\hline $\begin{array}{c}\text { Derajat } \\
\text { Kejenuhan }\end{array}$ & 0.93 & 0.85 & 0.34 & 0.93 \\
\hline
\end{tabular}

Gambar 3. Perhitungan Co, G, C \& DS, 2 Fase

Gambar diagram untuk waktu sinyal pada Simpang BCP dapat dilihat pada Tabel 6. 
Tabel 6. Signal Setting

\begin{tabular}{|c|c|c|c|c|c|}
\hline \multicolumn{6}{|c|}{ Signal Setting } \\
\hline Fase & Hijau (detik) & Kuning (detik) & All red (detik) & Merah (detik) & Co (detik) \\
\hline Utara - Selatan & 43.8 & 6 & 3 & 54.2 & 107 \\
\hline Timur - Barat & 50.7 & 6 & 3 & 47.3 & 107 \\
\hline
\end{tabular}

\section{Kesimpulan}

Hasil penelitian yang telah dilakukan yang mengacu pada Manual Kapasitas Indonesia (MKJI) 1997 dan pemodelan menggunakan PTV Vissim 20 (SP 08). Pada kinerja simpang BCP Kota Bekasi, Jawa Barat Dapat ditarik kesimpulan sebagai berikut: Ruas Jalan Ahmad Yani utara dengan sinyal lalu lintas diperoleh rata-rata hasil tundaan dan panjang antrian sebesar 34.4 detik, sehingga tingkat pelayanan simpang dengan menggunakan sinyal yaitu D (Kurang Baik). Jalan Ahmad Yani Selatan dengan sinyal lalu lintas diperoleh rata-rata hasil tundaan dan panjang antrian sebesar 40.1 detik, sehingga tingkat pelayanan simpang dengan menggunakan sinyal yaitu D (Kurang Baik). Jalan Mayor Madmuin Hasibuan dengan sinyal lalu lintas diperoleh rata-rata hasil tundaan dan panjang antrian sebesar 31.8 detik, sehingga tingkat pelayanan simpang dengan menggunakan sinyal yaitu D (Kurang Baik). Jalan KH Noer Ali dengan sinyal lalu lintas diperoleh rata-rata hasil tundaan dan panjang antrian sebesar 104.5 detik, sehingga tingkat pelayanan simpang dengan menggunakan sinyal yaitu F (Buruk Sekali). Jalan Simpang BCP (Bekasi Cyber Park). Hasil analisis kinerja Simpang BCP 2 fase dengan metode Manual Kapasitas Jalan Indonesia (MKJI) 1997 dan melalui pemodelan PTV VISSIM pada kondisi eksisting / saat pembangunan tol becakayu, menunjukan tingkat rata-rata pelayanan (LOS_E), Panjang antrian rata-rata (Qlen) sebesar $115 \mathrm{~m}$, dan tundaan simpang (VehDelay) sebesar $52.69 \mathrm{det} / \mathrm{skr}$.

\section{Daftar Pustaka}

[1] S. Sistri, "Kelangsungan Penggunaan Kontrasepsi di Indonesia," Kesmas J. Kesehat. Masy. Nas. (National Public Heal. Journal), vol. 3, no. 5, pp. 206-211, 2009. doi: 10.21109/kesmas.v3i5.211

[2] J. Tipka, "Proyeksi penduduk berlipat ganda di Kabupaten Maluku Tengah," BAREKENG J. IImu Mat. dan Terap., vol. 5, no. 2, pp. 31-34, 2011. doi: 10.30598/barekengvol5iss2pp31-34

[3] S. Solikatun and Y. Masruroh, "Kemiskinan Dalam Pembangunan," J. Anal. Sosiol., vol. 3, no. 1, 2014. doi: 10.20961/jas.v3i1.17450

[4] I. B. P. Widiarta, "Analisis Pemilihan Moda Transportasi Untuk Perjalanan Kerja," Univ. Udayana. Bali, 2010. Available at: Google Scholar

[5] C. N. Azka, R. Hidayat, and W. Ramadhana, "Analisis Pemodelan Pemilihan Moda Transportasi Ke Kampus oleh Mahasiswa Universitas Muhammadiyah Aceh," Tameh J. Civ. Eng., vol. 10, no. 1, pp. 1-8, 2021. doi: 10.37598/tameh.v10i1.123

[6] R. Syahbani, "Implementasi Kebijakan Pemerintah Provinsi DKI Jakarta tentang Pola Transportasi Makro dalam Menanggulangi Kemacetan di DKI Jakarta Tahun 20142015 (Studi Pada Penggunaan Moda Transportasi Massal Tr." 2017. Available at: Google Scholar

[7] G. T. Y. Hakim, "Analisis Karakteristik Parkir Kendaraan Pada Area Parkir Rumah Sakit Saiful Anwar Malang." ITN MALANG, 2019. Available at: Google Scholar

[8] J. M. Mubarok, "Analisis karakteristik dan kebutuhan lahan parkir Rumah Sakit Umum Daerah Sleman (analysis of characteristic and parking requirements at Regional Public Hospital In Sleman)." Universitas Islam Indonesia, 2019. Available at: Google Scholar

[9] M. Saefullah, M. A. Ihami, and K. Kulsum, "Usulan Penataan Ruang Parkir Dengan Pendekatan Simulasi Di Universitas X," J. Tek. Ind. Untirta, vol. 3, no. 2, 2015. Available at: Google Scholar

[10] R. B. S. Putera, A. Afifuddin, and R. P. Widodo, "Revitalisasi sumberdaya air sungai Kalimalang sebagai strategi pemanfaatan lahan di Kota Bekasi (Studi Kasus Kawasan Sungai Kalimalang, Kota Bekasi, Jawa Barat)," Respon Publik, vol. 14, no. 4, pp. 89-96, 2020. Available at: Google Scholar 
[11] A. Mufhidin and E. Subiastuti, "Traffic Analysis Due To Development on Off Ramp Becakayu Highway," IJTI Int. J. Transp. Infrastruct. eISSN 2597-4769 pISSN 2597-4734, vol. 4, no. 1, pp. 36-43, 2020. doi: 10.29138/ijti.v4i1.1163

[12] H. Riajaya, K. Orlando, and P. L. Samputra, "Evaluasi tingkat kepuasan masyarakat terhadap kebijakan tarif tol Becakayu," JPED (Jurnal Perspekt. Ekon. Darussalam)(Darussalam J. Econ. Perspect., vol. 5, no. 2, pp. 141-162, 2019. doi: $10.24815 / j p e d . v 5 i 2.13196$

[13] R. M. K. Ghazy, "Pengendalian Pencemaran Udara Terkait Pembangunan Jalan Tol Bekasi-Kampung Melayu (Studi di Kantor Dinas Lingkungan Hidup Kota Bekasi)." Universitas Brawijaya, 2017. Available at: Google Scholar

[14] N. W. Haryanto, W. I. Fipiana, and A. Pramonohadi, "Kajian kinerja simpang tak bersinyal JIn Inspeksi Sal. Kalimalang-JIn Cipinang Indah Raya II, Kalimalang, Jakarta Timur.," J. KaLIBRASI-Karya Lintas IImu Bid. Rekayasa Arsitektur, Sipil, Ind., vol. 10, 2015. Available at: Google Scholar

[15] V. Winodya, "Peran media sosial instagram@ jokowi dalam komunikasi politik Presiden Joko Widodo saat peresmian jalan tol." Universitas Katholik Soegijapranata Semarang, 2021. Available at: Google Scholar 